\title{
An elegant mind: Learning and memory in Caenorhabditis elegans
}

\author{
Evan L. Ardiel and Catharine H. Rankin ${ }^{1}$ \\ Brain Research Centre and Department of Psychology, University of British Columbia, Vancouver, British Columbia V6T 2B5, Canada
}

\begin{abstract}
This article reviews the literature on learning and memory in the soil-dwelling nematode Caenorhabditis elegans. Paradigms include nonassociative learning, associative learning, and imprinting, as worms have been shown to habituate to mechanical and chemical stimuli, as well as learn the smells, tastes, temperatures, and oxygen levels that predict aversive chemicals or the presence or absence of food. In each case, the neural circuit underlying the behavior has been at least partially described, and forward and reverse genetics are being used to elucidate the underlying cellular and molecular mechanisms. Several genes have been identified with no known role other than mediating behavior plasticity.
\end{abstract}

Historically, it was believed that even if they were capable of learning, the nervous systems of invertebrates were too different to be instructive on human cognition. In the 1960s, Kandel and colleagues began studying learning in the marine mollusc Aplysia (Kandel and Tauc 1965). Using this system, they were able to relate behavioral plasticity to changes at specific synapses of identified neurons, and began a biochemical analysis of these neuronal changes, uncovering a role for CAMP, PKA, and CREB. In the 1970s, Benzer and colleagues began a genetic dissection of learning in the fruit fly Drosophila melanogaster (Quinn et al. 1974; Dudai et al. 1976). They established an associative learning assay (Quinn et al. 1974) and conducted a forward genetic screen, identifying the first learning mutant, dunce (Dudai et al. 1976). Since then, many genes have been cloned, and the biological basis of learning has proven to be highly conserved (Barco et al. 2006; Skoulakis and Grammenoudi 2006). Today there is no question as to the relevance of invertebrate research in the field of learning and memory.

At about the same time that Kandel was beginning his work with Aplysia, Sydney Brenner chose Caenorhabditis elegans as the organism in which to study development and the nervous system (Brenner 1974). Today this transparent nematode is the world's best understood animal. It's small size $(\sim 1 \mathrm{~mm})$, short life cycle $(<3 \mathrm{~d})$, and ease of cultivation make it perfect for the laboratory, and its mode of reproduction is ideal for genetic analysis-selffertilizing hermaphrodites can be easily inbred or crossed with males. The genome has been mapped and sequenced, and there are thousands of mutants and RNAi constructs readily available for researchers. Furthermore, C. elegans has an invariant cell lineage and relatively simple morphology-959 cells make up the entire adult hermaphrodite (Sulston and Horvitz 1977; Sulston et al. 1983). Using serial section electron micrographs, White et al. (1986) were able to construct a neural wiring diagram of the hermaphrodite's 302 neurons. They found about 5000 chemical synapses, 600 gap junctions, and 2000 neuromuscular junctions, the location of which were fairly consistent between animals. With its invariant cell lineage and reproducible connectome, C. elegans was initially viewed as a genetically hardwired automaton that could swim forward or backward. It has since

\footnotetext{
${ }^{1}$ Corresponding author.

E-mail crankin@psych.ubc.ca; fax (604) 822-6923.

Article is online at http://www.learnmem.org/cgi/doi/10.1101//m.960510.
}

proven to be exquisitely sensitive to its environment, displaying remarkable behavioral plasticity. Here we review the literature on learning and memory in C. elegans. The paradigms covered can be roughly divided into three sections: nonassociative learning, associative learning, and imprinting. The first section outlines the work that has been done on the first form of learning characterized in C. elegans-habituation, which is subdivided into short-term, long-term, and context-dependent memory. The section on associative learning highlights the worm's ability to learn and remember relevant environmental stimuli, including smells, tastes, temperatures, and oxygen levels, and the last section describes the formation of imprints during larval development. The strength of C. elegans for learning and memory studies will be evident as findings are discussed from the level of genes, circuits, and behaviors. We have tried to include all relevant publications and apologize for any unintentional omissions.

\section{Nonassociative learning \\ Mechanosensory habituation}

\section{Short-term memory}

Rankin et al. (1990) were the first to characterize learning and memory in C. elegans. They studied plasticity of the "tapwithdrawal response" (TWR), a behavior whereby worms swim backward in response to a nonlocalized mechanical stimulus generated by tapping the Petri plate containing the worm. The magnitude of this reversal response is around $1 \mathrm{~mm}$ (roughly the length of the worm), but this can change with experience. Repeated administration of the tap results in a decrement of both the amplitude and the frequency of the response (Fig. 1A). Rankin et al. (1990) showed that a dishabituating stimulus (brief electric shock) facilitated the decremented response, suggesting that the decrement was due to habituation and not sensory/ motor fatigue or adaptation. As in other organisms, habituation and spontaneous recovery from habituation were dependent upon the interstimulus interval (ISI), prompting Rankin and Broster (1992) to hypothesize that there were multiple molecular mechanisms underlying habituation. Shorter ISIs resulted in faster and deeper habituation, as well as faster recovery. ISIdependent recovery from habituation is seen in other organisms and serves as an additional way to distinguish habituation from sensory adaptation or fatigue. With a highly characterized tap 

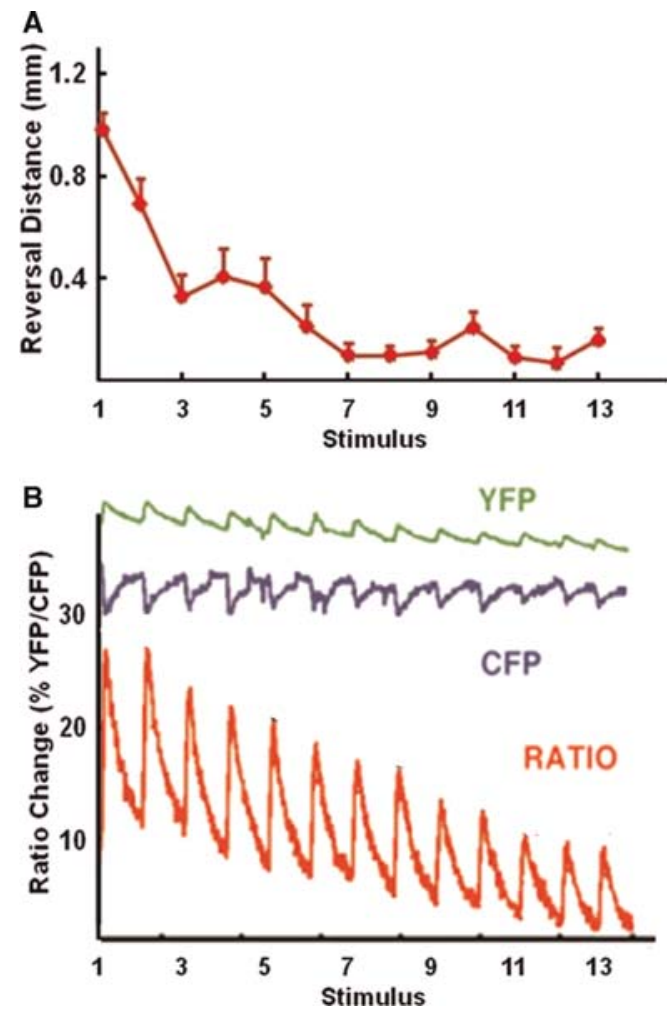

Figure 1. The behavioral and cellular responses to mechanical stimulation decrement following repeated administration at 10-sec intervals. (A) Tapping the side of the worm's Petri plate induces the tap-withdrawal response, in which worms swim backward for about $1 \mathrm{~mm}$ (approximately one worm length). The magnitude of the reversal decreases to an asymptotic level of responding after about seven taps at a 10-sec ISI. Error bars, SEM. (B) Using cameleon to measure the magnitude of touch-induced calcium currents in ALM, where intracellular calcium concentration positively correlates with changes in the YFP/CFP fluorescence ratio. Depicted is a representative trace demonstrating that repeatedly poking the worm leads to a decrease in the calcium response of ALM. (Figure from Kindt et al. 2007 and reprinted with permission from Elsevier (c) 2007.)

habituation behavioral paradigm, it was now possible to use the power of $C$. elegans to investigate the mechanisms underlying habituation.

The first step was to identify the neural circuitry underlying the TWR. In 1985, Chalfie et al. used laser ablation to determine which neurons were mediating the worm's reversal response to anterior touch and its forward acceleration response to posterior touch. The nonlocalized mechanical stimulus from a tap activates both the anterior and posterior mechanosensory neurons. Using the circuits described by Chalfie et al. (1985) in conjunction with the neural wiring diagram (White et al. 1986), Wicks and Rankin (1995) identified the mechanosensory cells (ALM, AVM, PLM, and PVD) and interneurons (AVD, AVA, AVB, PVC, and DVA) mediating the TWR. Ablation of the posterior touch cells (PLML/R) resulted in worms that always reversed to tap, while ablation of the anterior touch cells (ALML/R and AVM) resulted in worms that always accelerated forward in response to tap. Thus, the TWR arises from an integration of two competing subcircuits. By ablating the anterior touch cells or the posterior touch cells, Wicks and Rankin (1996) showed that the behavioral output of each subcircuit habituated with repeated stimulation. Importantly, the acceleration and reversal responses habituated with distinct kinetics that integrated in a manner consistent with tap habituation in the unablated animal. Kitamura et al. (2001) studied habituation of the anterior subcircuit by repeatedly touching the anterior half of the worm with an eyelash. They found that the kinetics of habituation at a 15-sec ISI was unaffected by the loss of AVA, AVB, or PVC interneurons, but the loss of AVD resulted in faster habituation.

With a well-defined neural circuit underlying the behavior of interest, the next step was to localize the site of plasticity. Downstream from the mechanosensory neurons, the interneurons and motor neurons underlying the TWR largely overlap with those mediating spontaneous reversals for exploration and reversals induced by a thermal stimulus (Gray et al. 2005). In fact, the AVD, AVA, AVB, and PVC, interneurons are required for coordinated forward and backward movement and have been called the command interneurons by Chalfie et al. (1985). Wicks and Rankin (1997) tested whether repeated administration of tap also decremented other types of reversal behaviors. They found that tap habituation training had no effect either on the frequency or magnitude of spontaneous reversals or on the magnitude of reversals elicited by a heated probe. This suggests that the locus of mechanosensory habituation is in a part of the circuit unique to the TWR, i.e., the touch cells and/or the synapses between the touch cells and the interneurons. Now the hunt for the underlying molecular mechanism could begin.

In 2003, Suzuki et al. demonstrated that repeated activation could alter the response properties of the mechanosensory neurons. Using the genetically encoded calcium reporter, cameleon, they found that repeatedly poking the anterior of the worm with a glass probe resulted in a cell-wide reduction in calcium response in the anterior touch cell, ALM (Fig. 1B). A similar reduction in calcium response was seen following repeated stimulation of the posterior touch cell, PLM (Kindt et al. 2007). Thus, attenuation of touch cell excitability with repeated activation correlates with decreased behavioral responding from tap habituation. To test if habituation arose from a desensitization of the mechanoreceptor, O'Hagan et al. (2005) used whole-cell patch-clamp recording to measure mechanoreceptor currents in the posterior touch cell, PLM. They found that repeatedly poking the cell body with a glass probe had no effect on the touch-evoked mechanoreceptor current. This finding suggests that the site of mechanosensory habituation is downstream from mechanotransduction.

A recent study provides a potential mechanistic link between repeated activation of touch cells and the decremented calcium current described by Suzuki et al. (2003). Cai et al. (2009) identified a $\mathrm{K}^{+}$channel (shw-3) and an accessory subunit (mps-1) with a role in regulating touch sensitivity. Expressed in the anterior (ALM) and posterior (PLM) touch cells (Bianchi et al. 2003), mps-1 encodes a single-pass transmembrane protein belonging to the vertebrate KCNE family of proteins that modulate poreforming $\mathrm{K}^{+}$channels. mps-1 loss-of-function mutants exhibited a decreased TWR compared with wild-type worms, a phenotype that could be rescued by expressing either wild-type MPS- 1 or a transgenic version with an inactivated kinase domain (Cai et al. 2009). Although they had a wild-type TWR, the worms with inactivated MPS-1 were deficient in habituation to tap at both short and long ISIs, requiring 10 times more taps to habituate and recovering almost instantaneously (Cai et al. 2009). Cai et al. (2009) showed that MPS-1 kinase activity inhibited SHW-3 $\mathrm{K}^{+}$currents and that the two proteins formed a complex in touch cells. They propose that repeated activation of the touch cells results in autophosphorylation of the SHW-3-MPS-1 complex, thus diminishing $\mathrm{K}^{+}$flux and prolonging the duration of mechanoreceptor potentials. This would slow the recovery from inactivation of EGL-19 (the L-type calcium channel mediating touch-evoked calcium currents) (Suzuki et al. 2003) and dampen cell 
excitability. Consistent with this model, shw-3 loss-of-function mutants had a diminished TWR, as though they were already habituated. How the kinase activity of mps-1 is activated by repeated mechanical stimulation is unknown.

Rankin and Wicks (2000) found that disrupting glutamate neurotransmission also altered habituation to tap. eat 4 encodes the $C$. elegans ortholog of the mammalian vesicular glutamate transporter (VGLUT1) and is expressed in several neurons, including the touch cells underlying the TWR (Lee et al. 1999). Loss-of-function eat-4 mutants had a wild-type TWR but habituated to tap more quickly at both a 10 - and 60-sec ISI and failed to dishabituate following a brief electric shock. This suggests that modulation of glutamate release is an important component of mechanosensory habituation, perhaps downstream from cell excitability or as part of a parallel pathway. Forward genetic screens will help to identify other components underlying mechanosensory habituation. One such screen was conducted by $\mathrm{Xu}$ et al. in 2002, but the mutant phenotypes have yet to be mapped to genes.

\section{Long-term memory}

Under the appropriate training regime, worms show long-term memory for tap habituation (Beck and Rankin 1997). Adult worms given four blocks (each separated by $1 \mathrm{~h}$ ) of 20 taps at a 60-sec ISI had decremented TWRs when tested $24 \mathrm{~h}$ after training (Beck and Rankin 1995; Rose et al. 2002). At this 24-h time point, there was no evidence for long-term retention of habituation in worms massed trained with 80 taps or worms given distributed training with a 10 -sec ISI. The fact that a $60-\mathrm{sec}$, but not a 10 -sec, ISI induced long-term memory supports the hypothesis of multiple mechanisms of habituation. As would be expected for long-term memory, blocking protein synthesis during training (with heat shock) blocked consolidation of the memory (Beck and Rankin 1995). Long-term habituation was also sensitive to reconsolidation blockade-habituated worms given reminder taps followed by heat shock lost the memory of habituation training (Rose and Rankin 2006). These data suggest that long-term mechanosensory habituation shares features of long-term memory described in other organisms.

In mammalian systems, changes in glutamate receptor expression have been proposed as a mechanism of memory formation (Lüscher and Frerking 2001; Malinow and Malenka 2002). Rose et al. (2003) showed that the AMPA-type glutamate receptor subunit, GLR-1, was required for long-term habituation-glr-1 loss-of-function mutants habituated but did not retain decremented responses. Rose et al. (2003) monitored GLR-1 levels in a transgenic worm strain in which GLR-1 was fused to GFP (GLR-1::GFP). They found that long-term habituation was associated with a significant reduction in the size, but not the number, of the GLR-1::GFP clusters in the posterior ventral nerve cord (Fig. 2). The majority of these clusters are thought to be postsynaptic elements because they colocalize with presynaptic markers (synaptobrevin and a vesicular glutamate transporter) (Rongo et al. 1998; Burbea et al. 2002). Of more than 15 classes of glr-1 expressing neurons, at least seven have processes extending to the posterior ventral nerve cord, with the majority of the synapses belonging to the interneurons implicated in the TWR circuit. The decrease in GLR-1::GFP expression associated with long-term habituation is likely occurring at these synapses. Thus, it is hypothesized that short-term habituation is mediated by multiple mechanisms in the touch cells and long-term memory is linked to changes in the strength of the glutamatergic synapses in the interneurons.

Ebrahimi and Rankin (2007) studied the effects of early habituation training on adult behavior. They stimulated various aged larvae with five blocks (separated by $1 \mathrm{~h}$ ) of 20 taps at a 60 -sec ISI. They found that training in the first of four larval stages (L1) led to larger TWRs in young adults, but smaller responses in older worms, compared with untrained controls. As in the longterm habituation paradigm described above, this effect was dependent upon $g l r-1$. Furthermore, both $g l r-1$ mRNA levels and GLR-1::GFP cluster size correlated with TWR magnitude. Interestingly, stimulating worms later in larval development had no effect on the TWR of young adults but still decremented the response of older adults. Adults massed trained in L1 with a tap a minute for $100 \mathrm{~min}$ did not differ from unstimulated controls, nor did those receiving distributed training with a 10-sec ISI. The decrement of the tap response observed in older adults was sensitive to reconsolidation blockade while the facilitation observed in young adults was not, suggesting that these two processes were mediated by different mechanisms. This study demonstrates that larval stimulation can affect adult behavior, but the effect depends on the timing and pattern of stimulation.

Emtage et al. (2009) also studied the effects of early patterned stimulation on adult behavior and identified a gene mediating changes in AMPA receptor localization. They trained L1 larvae with seven blocks (separated by $1 \mathrm{~h}$ ) of 15 taps at a 60 -sec ISI. In contrast to Ebrahimi and Rankin (2007), Emtage et al. (2009) found that young adults stimulated in L1 had a decreased TWR magnitude, as measured by the number of quarter body bends executed in the response. This discrepancy may be the result of a different training regime, rearing condition $\left(20^{\circ} \mathrm{C}\right.$ vs. $\left.25^{\circ} \mathrm{C}\right)$, behavioral measure, or time of training/testing. Emtage et al. (2009) also looked at habituation and found that young adults stimulated in L1 stopped responding to mechanical stimuli more quickly than controls (a measure of response frequency rather than magnitude). Long-term memory of early training required $g l r-1$, as well as a second AMPA-type glutamate receptor subunit, glr-2. Emtage et al. (2009) reported a significant increase in the number of GLR-2::GFP clusters in the anterior ventral nerve cord of young adults stimulated in L1 and showed that the scaffolding molecule, MAGI-1, interacted with the intracellular domain of GLR-2 to regulate AMPA receptor localization following habituation training.

\section{Effect of context in short-term mechanosensory habituation}

The kinetics with which worms habituate to tap is dependent upon the context in which the stimuli are given. In the laboratory, worms are reared on agar Petri plates with a bacterial food source. When tested in the absence of the bacteria, the proportion of worms responding to tap decreased more rapidly with repeated stimulation at a 10-sec ISI than did worms tested in the presence of bacteria, i.e., worms habituated to tap faster when stimulated off of food (note that in this case, the effect was on response frequency, there was no difference in habituation of response magnitude, suggesting that there is independent regulation of habituation of response frequency and response magnitude) (Kindt et al. 2007). Mutants in which dopaminergic signaling was disrupted habituated to tap with the rapid kinetics of wildtype worms tested off of food (Sanyal et al. 2004; Kindt et al. 2007). It was hypothesized that the texture of bacterial lawns stimulated dopamine release, which altered the functional properties of the touch cells through the D1-like dopamine receptor, DOP-1 (Sawin et al. 2000; Sanyal et al. 2004; Kindt et al. 2007). Calcium-imaging experiments in various mutant backgrounds revealed that dopamine slowed the decrement of touch-evoked calcium currents in ALM via intracellular calcium release and PKC activity downstream from a Gq/PLC- $\beta$ signaling cascade (Kindt et al. 2007). Thus, more rapid habituation kinetics in the 


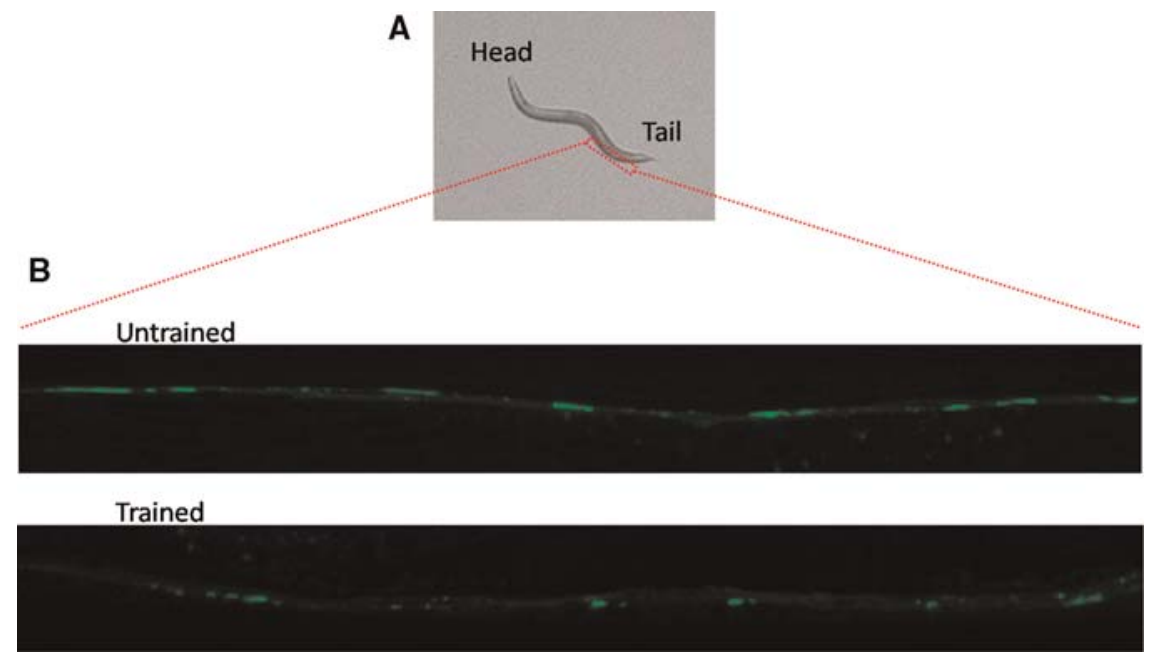

Figure 2. GLR-1::GFP imaging in 5-d-old worms $24 \mathrm{~h}$ after stimulation. ( $A$ ) The red box indicates the portion of the ventral nerve cord that was imaged. (B) Representative images of GLR-GFP clusters in a worm given a single control tap (untrained) or long-term habituation training (trained). Trained worms showed a significant reduction in the size, but not the number of clusters.

absence of food correlates with more rapid attenuation of ALM excitability.

The context in which habituation occurs can also influence behavior in subsequent tests. This reflects associative learning in the form of context conditioning. Rankin (2000) found that worms trained with 30 taps in the presence of a chemosensory cue (sodium acetate) showed increased retention of training when retested $1 \mathrm{~h}$ later in the presence of that same cue, compared with worms never exposed to the cue or those only exposed during training or testing. The enhanced memory required that the cue be predictive of the tap, as worms exposed to sodium acetate for $1 \mathrm{~h}$ before (CS-pre-exposure) or after (extinction) training showed no context conditioning.

\section{Chemosensory habituation}

Colbert and Bargmann (1995) observed that continuous exposure of C. elegans to an attractive odorant eventually resulted in a loss of chemotactic response to that odorant. Unlike mammals, C. elegans olfactory neurons express many odorant receptors. Despite this, the loss of chemotactic response was odorant specific, suggesting it was not due to a cell-wide reduction in excitability. Interestingly, prolonged exposure to one odorant was actually shown to facilitate the chemotactic response to another odorant sensed by the same neuron (Colbert and Bargmann 1997). The molecular mechanisms underlying olfactory adaptation have been intensely investigated and consist of several signaling cascades (Table 1) dependent on the odorant, neuron, and assay. These complex overlapping pathways demonstrate how a few neurons can be used to carry many signals.

To qualify as habituation (a form of nonassociative learning) and not sensory adaptation, the decremented response to a chemical cue should be readily
Table 1. Genes implicated in olfactory adaptation

\begin{tabular}{|c|c|c|c|}
\hline Process & Genes & Product & Reference \\
\hline \multirow[t]{3}{*}{ cGMP signaling } & odr-1 & guanylyl cyclase & L'Etoile and Bargmann (2000) \\
\hline & egl-4 & $\begin{array}{l}\text { cGMP-dependent protein } \\
\text { kinase }\end{array}$ & L'Etoile et al. (2002) \\
\hline & $\operatorname{tax}-2$ & cGMP-gated ion channel & \\
\hline \multirow{2}{*}{$\mathrm{Ca}^{2+}$ signaling } & $\operatorname{tax}-6$ & calcineurin & Kuhara et al. (2002) \\
\hline & osm-9 & TRPV ion channel & Colbert and Bargmann (1995) \\
\hline \multirow[t]{2}{*}{ DAG signaling } & goa-1 & $\mathrm{G}_{\mathrm{o}} \alpha$ & Matsuki et al. (2006) \\
\hline & $\begin{array}{l}\text { egl-30 } \\
\text { dgk1; } \\
\text { dak-3 }\end{array}$ & $\begin{array}{l}\mathrm{G}_{\mathrm{q}} \alpha \\
\text { DAG kinase }\end{array}$ & \\
\hline Receptor desensitization & arr-1 & arrestin & Palmitessa et al. (2005) \\
\hline Ras-MAPK signaling & $\begin{array}{l}\text { let-60 } \\
\text { mek-2 }\end{array}$ & $\begin{array}{l}\text { Ras GTPase } \\
\text { MAP kinase kinase }\end{array}$ & Hirotsu and lino (2005) \\
\hline Transcriptional regulation & $t b x-2$ & T-box transcription factor & Miyahara et al. (2004) \\
\hline \multirow[t]{3}{*}{ Translational regulation } & $f b f-1$ & $\begin{array}{l}\text { Pumilio/Fem-3 RNA binding } \\
\text { protein }\end{array}$ & Kaye et al. (2009) \\
\hline & nos-1 & $\begin{array}{l}\text { NANOS RNA binding } \\
\text { protein }\end{array}$ & \\
\hline & $g / d-3$ & poly $(A)$ polymerase & \\
\hline
\end{tabular}

reversible following a novel or noxious stimulus, that is, by a dishabituating stimulus. Thus, a habituated animal can still sense the stimulus but is attending elsewhere until the stimulus becomes relevant, whereas an adapted animal cannot sense the stimulus until it is removed and sufficient time has passed for recovery. Bernhard and van der Kooy (2000) demonstrated that worms both habituated and adapted to odorants. First, they showed that chemotaxis to a point source of diacetyl was diminished by pre-exposure to $0.001 \%$ or $100 \%$ diacetyl, but not $0.01 \%$ or $25 \%$. Then they demonstrated that a dishabituating stimulus (centrifugation) returned to baseline the decremented response of worms pre-exposed to $0.001 \%$ diacetyl, but not those pre-exposed to $100 \%$ diacetyl, suggesting that worms habituated to $0.001 \%$ diacetyl and adapted to $100 \%$ diacetyl. Worms with a loss-of-function mutation in $g l r-1$ failed to habituate to diacetyl, implicating the AMPA-type glutamate receptor subunit, GLR-1, in chemosensory habituation (Morrison and van der Kooy 2001). Nuttley et al. (2001) showed that worms also habituated to benzaldehyde exposure, but $g l r-1$ was not required (Morrison and van der Kooy 2001). As Rankin and Wicks (2000) demonstrated with an electric shock following mechanosensory habituation, Nuttley et al. (2001) showed with centrifugation following benzaldehyde exposure: Wild-type worms dishabituate, but eat- 4 loss-of-function mutants do not. This suggests some conserved mechanisms of nonassociative learning across modalities.

\section{Effect of context on chemosensory habituation}

As in mechanosensory habituation, there is an associative component to chemosensory habituation. Nuttley et al. (2002) showed that habituation to benzaldehyde was inhibited in the presence of food. This suggests a learned association, making worms less likely to ignore benzaldehyde if it is predictive of food. Serotonin signaling underlies many food-related behavioral 
changes and is likely the mechanism by which food is encoded as the unconditioned stimulus in many paradigms discussed below. Consistent with this role, exogenous serotonin inhibited habituation to benzaldehyde in the absence of food. Furthermore, the presence of food had no effect on the habituation of serotonin deficient mutants, cat-4 and tph-1 (Nuttley et al. 2002).

Following odorant habituation, expression of the learned behavior can be modulated by contextual cues present during conditioning. Law et al. (2004) found that worms exposed to an odorant in the presence of a taste cue showed enhanced retention of olfactory habituation when challenged in the presence of that same cue (Law et al. 2004). Furthermore, Bettinger and McIntire (2004) demonstrated that worms previously adapted to an odorant under the influence of ethanol displayed decremented responses to that odorant only when intoxicated. Dopamine deficient cat-2 mutants were impaired in this state-dependent learning assay.

\section{Associative learning}

C. elegans exhibit a remarkable capacity to learn and remember the environmental features that predict good food, bad food, no food, or aversive stimuli; allowing worms to chemotax, thermotax, or aerotax to more favorable environments. This section discusses associative learning paradigms in which tastes, smells, temperatures, and oxygen levels are paired with various unconditioned stimuli.

\section{Taste as the conditioned stimulus}

Worms chemotax to various salts and water-soluble attractants, a behavior mediated mainly by the pair of ASE gustatory neurons (Bargmann and Horvitz 1991). Residual responses to $\mathrm{NaCl}$ in the absence of ASE can be attributed to ASI, ASG, and ADF (Bargmann and Horvitz 1991). Both $\mathrm{Na}^{+}$and $\mathrm{Cl}^{-}$are chemoattractants; $\mathrm{Na}^{+}$is sensed primarily by the left ASE neuron, ASEL, and $\mathrm{Cl}^{-}$primarily by the right one, ASER (PierceShimomura et al. 2001). In choice tests between diffusive gradients of specific concentrations of $\mathrm{Na}^{+}$and $\mathrm{Cl}^{-}$, naïve worms show no preference, migrating in equal numbers to both. However, Wen et al. (1997) employed a differential classical conditioning paradigm to show that preferences could change if one of the ions was paired with food or an aversive stimulus (i.e., garlic extract). Worms previously exposed to an ion in the presence of food preferentially migrated to it in the choice test, but worms previously exposed to an ion in the presence of garlic extract, preferentially migrated to the other ion. Control experiments showed that the learned preference and avoidance qualified as appetitive and aversive associative learning (respectively), as they required predictive pairing with the unconditioned stimulus, food or garlic. Wen et al. (1997) conducted a genetic screen and isolated the first learning mutants in C. elegans, lrn-1 and $l r n-2$. These mutants showed no detectable sensory impairment, but failed to respond to either appetitive or aversive conditioning. The mutations have yet to be mapped to genes.

In a different assay, Saeki et al. (2001) starved worms on plates with $\mathrm{NaCl}$ and then examined their propensity to migrate up a $\mathrm{NaCl}$ concentration gradient. They found that worms starved for $4 \mathrm{~h}$ on a plate containing $\mathrm{NaCl}$ migrated away from it in a subsequent choice test. The pairing of starvation with $\mathrm{NaCl}$ must have caused the aversion because animals starved on plates without $\mathrm{NaCl}$ did not develop it, nor did unstarved worms on $\mathrm{NaCl}$ containing plates. In addition to starvation, Hukema et al. (2008) demonstrated that worms could also learn to associate $\mathrm{NaCl}$ with aversive stimuli (glycerol or undiluted benzaldehyde). The switch of $\mathrm{NaCl}$ from attractant to repellent occurred gradually (maximizing after $4 \mathrm{~h}$ of starvation) and was readily reversible, within an hour if worms were starved in the absence of $\mathrm{NaCl}$ and within $10 \mathrm{~min}$ if $\mathrm{NaCl}$ was presented with food. Saeki et al. (2001) showed that learned aversion to $\mathrm{NaCl}$ generalized to other water-soluble attractants sensed by ASE, including cAMP, biotin, and lysine, suggesting that the changes were occurring at the cellular rather than the receptor level. Using a modified assay in which worms were soaked in a salt buffer without food for just $15 \mathrm{~min}$, Jansen et al. (2002) and Hukema et al. (2006) identified several components of the molecular pathways acting in at least four sensory neurons to mediate learned $\mathrm{NaCl}$ aversion. Relevant molecules include G $\gamma$ subunit GPC-1, G $\alpha$ subunits GPA- 1 and ODR-3, and TRPV channel subunits OCR-1, OCR-2, and OSM-9. In their model, initial $\mathrm{NaCl}$ attraction is mediated by ASE neurons, but prolonged exposure leads to the release of a signal from ASE that sensitizes the ASH, ADF, and ASI neurons (Fig. 3). Hukema et al. (2008) implicated serotonergic, dopaminergic, and glutamatergic signaling in this process.

Interestingly, Vellai et al. (2006) found that male worms were less proficient at salt starvation learning than hermaphrodites. They proposed that this sex-based learning deficit was the result of reduced insulin/IGF-1 signaling. Consistent with this hypothesis, both Vellai et al. (2006) and Tomioka et al. (2006) demonstrated a role for insulin-like signaling in the modulation of $\mathrm{NaCl}$ preference. $\mathrm{NaCl}$ starvation conditioning was defective in worms with mutations in genes encoding homologs of insulin (ins-1), insulin/IGF-I receptor (daf-2), PI 3-kinase (age-1), phosphoinositide-dependent kinase ( $p d k-1)$, and Akt/PKB (akt-1). Using cell-specific promoters, Tomioka et al. (2006) showed that expression of daf- 2 and age-1 in ASER, but not ASEL, was sufficient to rescue the learning deficit of the corresponding mutants, suggesting that the insulin-like signaling pathway was acting in ASER to modulate $\mathrm{NaCl}$ preference. They proposed the AIA interneurons as the source of the insulin-like peptide because INS-1 localized to their synaptic regions and killing them with a laser microbeam disrupted $\mathrm{NaCl}$ conditioning. In their model, insulin released by AIA interneurons provided feedback to ASER sensory neurons by activating the insulin/PI 3-kinase pathway (Fig. 3). PI 3-kinases phosphorylate $\mathrm{PIP}_{2}$ to $\mathrm{PIP}_{3}$, which activates PDK and Akt/PKB kinases. PTEN phosphatase, DAF-18 in C. elegans, catalyzes the opposite reaction: $\mathrm{PIP}_{3}$ to $\mathrm{PIP}_{2}$. Loss of daf-18 function therefore results in elevated $\mathrm{PIP}_{3}$ levels. Tomioka et al. (2006) showed that unconditioned daf-18 mutants already had an aversion to $\mathrm{NaCl}$, suggesting $\mathrm{PIP}_{3}$ may negatively regulate salt chemotaxis. In a suppressor screen for mutants reversing the $\mathrm{NaCl}$ aversion of daf-18 mutants, Tomioka et al. (2006) identified an egl-30 gain-of-function mutation. EGL-30 encodes G-protein subunit $G_{q} \alpha$, and in motor neurons, it was shown to positively regulate synaptic transmission (Lackner et al. 1999). Tomioka et al. (2006) propose that it is a balance between insulin/PI 3-kinase signaling and DAF-18 activity that determines whether $\mathrm{NaCl}$ is attractive or aversive, perhaps by regulating synaptic output of ASER via EGL-30. This insulin-like signaling pathway is also involved in thermosensory associative learning (Kodama et al. 2006; see below).

Although $\mathrm{NaCl}$ is used in salt conditioning assays, both the $\mathrm{Na}^{+}$and $\mathrm{Cl}^{-}$ions are salient cues. Insulin-like signaling in ASER mediates $\mathrm{NaCl}$ starvation conditioning, presumably by modulating preference for the anion, but worms also learn to avoid $\mathrm{Na}^{+}$ ions. Recently, Fu et al. (2009) showed that learned $\mathrm{Na}^{+}$(but not $\mathrm{Cl}^{-}$) aversion required DKF-2, a member of the D kinase family. $d k f-2$ encodes two isoforms, DKF-2A, which is expressed predominantly in intestinal cells (Feng et al. 2007) and DKF-2B, which is expressed in about 20 neurons, including ASEL and downstream interneurons (Fu et al. 2009). Interestingly, both intestinal DKF-2A and neuronal DKF-2B were required for $\mathrm{Na}^{+}$ 
$[\mathrm{NaCl}]$

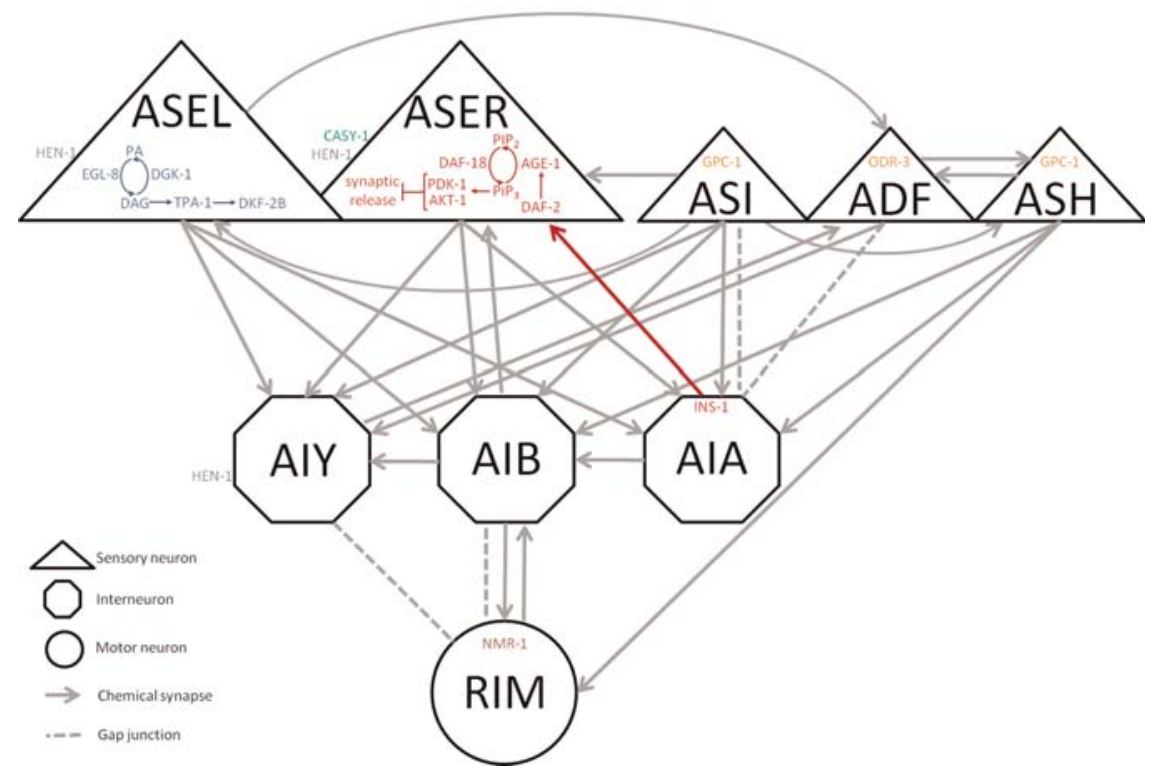

Figure 3. Cells and molecules implicated in learned $\mathrm{NaCl}$ aversion. Based on data from Hukema et al. (2006), Tomioka et al. (2006), Fu et al. (2009), Kano et al. (2008), Ikeda et al. (2008), Ishihara et al. (2002), and White et al. (1986).

conditioning, suggesting that DKF-2 mediates salt starvation conditioning by integrating environmental signals targeted to neurons and intestine (Fu et al. 2009). DKF-2B could be mediating learned $\mathrm{Na}^{+}$aversion by regulating synaptic output of ASEL (Fig. 3), body cavity neurons, and/or interneurons. Testing candidate mutants of various upstream regulators, $\mathrm{Fu}$ et al. (2009) showed that salt conditioning activated DKF-2 via a pathway containing EGL-8, a DAG-producing PLC- $\beta 4$ homolog and TPA-1, a DAG-activated PKC $\delta-\theta$ homolog.

Kano et al. (2008) proposed that retention of the learned $\mathrm{NaCl}$ aversion requires the NMDA receptor subunits, NMR-1 and NMR-2. Both $n m r-1$ and $n m r-2$ mutants learned to avoid $\mathrm{NaCl}$ after it was paired with starvation, but when left on the assay plate, these mutants accumulated at the $\mathrm{NaCl}$ point source more quickly than wild-type worms. This may have been the result of decreased retention of learned $\mathrm{NaCl}$ aversion or may have arisen from a locomotion phenotype, as $n m r-1$ mutants have been shown to have a lower probability of switching from forward to backward movement (Brockie et al. 2001). Expression of NMR-1 in a single-pair of interneurons (RIML/R) was sufficient to rescue wild-type behavior in the $\mathrm{NaCl}$ conditioning assay (Fig. 3).

\section{Smell as the conditioned stimulus}

Worms chemotax to volatile organic compounds released by their bacterial food source. Diacetyl is normally one such chemoattractant, but Morrison et al. (1999) showed that worms could learn to avoid it if it was previously presented with an aversive acetic acid solution. Conversely, Torayama et al. (2007) found that C. elegans became more attracted to butanone after pre-exposure to it in the presence of food, and Tsui and van der Kooy (2008) proposed that older worms displayed enhanced chemotaxis to benzaldehyde because of increased exposure to the pairing of volatile metabolites with the presence of an appetitive bacterial food source. Interestingly, increased attraction to benzaldehyde in aged worms was mediated by serotonin (Tsui and van der Kooy 2008) while butanone enhancement was not (Torayama et al.
2007), suggesting that there are multiple mechanisms for sensory integration.

Zhang et al. (2005) demonstrated that worms could learn to avoid odors associated with pathogenic bacteria, preferring those associated with familiar nonpathogenic strains. Given a choice between a lawn of pathogenic bacteria and a lawn of nonpathogenic bacteria at opposing sides of an assay plate, naïve worms preferentially migrated to the lawns of some strains of pathogenic bacteria, but this changed with experience. Aversive conditioning to pathogenic bacteria occurred quite rapidly, requiring only a 4 -h exposure to a pathogen. Using a four-choice maze with familiar and unfamiliar pathogenic and nonpathogenic bacteria, Zhang et al. (2005) showed that worms not only avoided known pathogens but also preferred known nonpathogens. Thus, there is an attractive and aversive component to food choice. Zhang et al. (2005) showed that infection, the unconditioned stimulus, was encoded by a serotonin signal from ADF. Serotonindeficient $t p h-1$ (tryptophan hydroxylase) mutants had no learned bacterial preference, and worms exposed to exogenous serotonin learned to avoid pathogens faster. There are at least five serotonergic neuronal cell types in the hermaphroditic form of C. elegans, ADF, NSM, HSN, AIM, and RIH (Sze et al. 2000). Rescuing tph-1 expression in $\mathrm{ADF}$ alone was sufficient to rescue learned aversion behavior, but not learned attraction behavior. Rescuing $t p h-1$ expression in both ADF and NSM restored wild-type behavior, suggesting ADF controls food aversion behavior and NSM controls food attraction behavior. Zhang et al. (2005) observed elevated levels of serotonin in the ADF chemosensory neuron following pathogen exposure and showed that the increase was mediated by both transcriptional and post-transcriptional mechanisms. The serotonin-gated chloride channel, MOD-1, is the postulated target of the serotonin signal from ADF, as mod-1 loss-of-function mutants did not learn to avoid pathogens. mod-1 transgenic rescue strains suggest that the serotonin receptor can function in multiple interneurons to mediate food choice. In addition to pathogenicity, ease of ingestion also affects a bacterium's ability to support worm growth. Avery and Shtonda (2003) showed that small, nonsticky bacteria make for the best food. Prior experience with high-quality food made L1 worms more likely to explore when placed on a lawn of low quality food (nonpathogenic, but hard-to-eat bacteria) (Shtonda and Avery 2006). This suggests that worms remember not only the smell of pathogens but also the satiation status associated with previous conditions.

\section{Temperature as the conditioned stimulus}

Hedgecock and Russell (1975) observed that well-fed worms thermotax to their previous cultivation temperature (between $15^{\circ} \mathrm{C}$ and $25^{\circ} \mathrm{C}$ ) and then move isothermally at that temperature. Using a radial temperature gradient assay (Fig. 4) and laser ablation of identified neurons, Mori and Ohshima (1995) described a neural circuit for thermotaxis, in which they proposed AFD was the major thermosensory neuron, AIY was the interneuron mediating thermophilic movement, AIZ was the interneuron mediating cryophilic movement, and RIA was the 
A

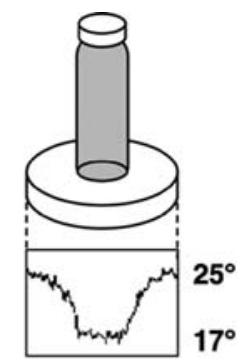

B

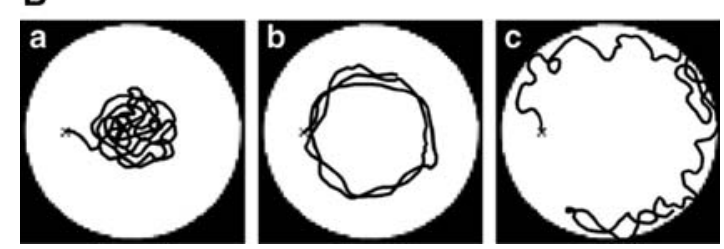

Figure 4. Radial temperature gradient assay. (A) The temperature gradient of $17^{\circ} \mathrm{C}-25^{\circ} \mathrm{C}$ is established by placing a vial of frozen acetic acid in the center of a $9-\mathrm{cm}$ agar plate. (B) Sample tracks of animals reared at $17^{\circ} \mathrm{C}(\mathrm{a}), 20^{\circ} \mathrm{C}(\mathrm{b})$, and $25^{\circ} \mathrm{C}$ (c). (Figure from Mohri et al. 2005 and reprinted with permission from the Genetics Society of America $(\odot) 2005$.)

interneuron integrating the thermo- and cryophilic drives. Others have proposed different models. Ryu and Samuel (2002) monitored the behavior of individual worms in temperature gradients. They observed cryophilic movement and isothermal tracking but found no evidence for a thermophilic drive. Also monitoring individual worms, Yamada and Ohshima (2003) recorded neither thermo- nor cryophilic movement, but Zariwala et al. (2003) saw both. Discrepancies in thermotaxis behavior arise as the result of procedural differences. Importantly, thermophilic migration is not observed upon initial transfer to the gradient, in steep temperature gradients, or if the worm is placed too far from the cultivation temperature (Ito et al. 2006; Jurado et al. 2009). However, directed movement up and down temperature gradients can be considered a stable and generalized behavior.

The sensory neurons themselves store a memory of the previous cultivation temperature (Kimura et al. 2004; Kuhara et al. 2008). AFD responds to thermal stimuli above a threshold temperature, which is dependent upon the cultivation temperature, e.g., $15^{\circ} \mathrm{C}, 17^{\circ} \mathrm{C}$, and $21^{\circ} \mathrm{C}$ for animals cultivated at $15^{\circ} \mathrm{C}, 20^{\circ} \mathrm{C}$, and $25^{\circ} \mathrm{C}$, respectively (Clark et al. 2006). Thermal upshifts above the threshold temperature increased intracellular calcium, while downshifts decreased intracellular calcium (Clark et al. 2006). By severing the dendrite, Clark et al. (2006) showed that a memory of cultivation temperature was stored in the sensory ending of AFD. Downstream from thermosensation, the DGK-3 diacylglycerol kinase appears to be acting in AFD as a thermal memory molecule modulating the temperature range of synaptic output (Biron et al. 2006), and the neuron-specific calcium sensor, NCS-1, functions in AIY to mediate isothermal tracking (Gomez et al. 2001). Olfactory neuron AWC has recently been included as a secondary thermosensory neuron (Biron et al. 2008; Kuhara et al. 2008). Depending on the specifics of the experimental procedure, AWC was shown to respond either deterministically to thermal stimuli above a threshold temperature corresponding to the cultivation temperature (Kuhara et al. 2008) or stochastically with calcium events whose frequency was stimulus correlated in a manner dependent upon cultivation temperature (Biron et al. 2008). The response properties of AFD and AWC provide a cellular correlate for the memory of previous cultivation temperature.

Importantly, temperature preference can be modified via classical conditioning. In 1975, Hedgecock and Russell reported that worms in starved or overcrowded colonies actually dispersed from their cultivation temperature, presumably due to a learned association between temperature and a lack of food. Although starvation had no effect on the response properties of the AFD sensory neurons, it led to decremented thermal-induced calcium responses in the AIZ interneurons (Kodama et al. 2006). To investigate the molecular mechanisms underlying thermosensory conditioning, Mohri et al. (2005) performed a genetic screen looking for mutants that failed to avoid cultivation temperatures paired with starvation. One of their mutations mapped to ins-1 (Kodama et al. 2006). Opposite of its role in salt conditioning (discussed above), INS-1 was found to antagonize DAF-2 insulinlike signaling in thermosensory associative learning (Kodama et al. 2006). Calcium imaging experiments showed that INS-1 was required for the starvation-induced inhibition of AIZ, as was TAX-6, an ortholog of calcineurin A (Kodama et al. 2006; Kuhara and Mori 2006). Taken together, these studies suggest that thermosensory neurons store a memory of cultivation temperature, but a neuroendocrine system acts in the interneurons to modulate the circuit in response to feeding state. Although many researchers consider this thermotaxis behavior to be associative learning, an alternative hypothesis is that worms store a memory for cultivation temperature, but ignore this memory in the absence of food (Chi et al. 2007). Further studies using appropriate experimental conditions and controls are required to distinguish between these hypotheses.

\section{Oxygen as the conditioned stimulus}

Cheung et al. (2005) showed that oxygen preference could also be altered by experience. Challenged in an oxygen gradient of $0 \%-21 \%$, worms reared under standard laboratory conditions accumulated at $5 \%-12 \% \mathrm{O}_{2}$; but after cultivation with food for $4-6 \mathrm{~h}$ at low $\mathrm{O}_{2}$ levels $(1 \%)$, worms preferentially migrated to $0 \%-7 \% \mathrm{O}_{2}$. The altered aerotaxis behavior seems to have resulted from a learned association of low $\mathrm{O}_{2}$ levels with food because worms cultivated without food for $6 \mathrm{~h}$ at $1 \% \mathrm{O}_{2}$ continued to accumulate at $5 \%-12 \% \mathrm{O}_{2}$. AQR, $\mathrm{PQR}$, and URX are the primary sensory neurons mediating aerotaxis. They coexpress five soluble guanylate cyclases (GCY-32, -34, -35, -36, and -37) (Yu et al. 1997; Cheung et al. 2004; Gray et al. 2004), heme-binding proteins that can interact with gases via the heme iron. While naïve $g c y$-35 and gcy-36 mutants had altered aerotaxis behavior, gcy-32 and $g c y-34$ mutants were largely normal, except that they could not change their behavior with experience, implicating GCY-32 and GCY-34 in oxygen-mediated learning.

\section{Imprinting}

Imprints are long-term memories formed during specific stages of development or physiological states. Remy and Hobert (2005) demonstrated that C. elegans form an olfactory imprint of their surroundings in the period after hatching. Larval exposure to certain odorants influenced adult behavior upon re-exposure; i.e., the imprinted odorants became more attractive and induced egg-laying. This behavioral plasticity qualifies as imprinting because memory acquisition was restricted to the first larval stage and was not expressed until worms became egg-laying adults. Only odorants sensed by AWC olfactory neurons could be imprinted. Although AWC senses multiple odorants, Remy and Hobert (2005) showed the imprint to be odorant and even concentration specific. Imprint formation required that the odorant be predictive of food, as no imprint was formed if an odorant was presented in the absence of food. Therefore, imprinting allows $C$. elegans to remember smells that predicted food when they hatched. They can use this memory to deposit their own eggs at similar smelling sites. This behavior is mediated 
by the AIY interneurons, which are postsynaptic to AWC. The G protein-coupled seven-transmembrane receptor, SRA-11, functions in AIY to store the imprint by some yet unknown mechanism.

As in mammals, ethanol exposure causes dose-dependent depressive effects on the behavior of $C$. elegans (locomotion and egg-laying), and intoxication occurs at about the same internal ethanol concentration (Davies et al. 2003). Ethanol is aversive to naïve worms, but Lee et al. (2009) showed that it becomes attractive after a 4 -h pre-exposure. Both dopaminergic and serotonergic signaling mediate this effect, as cat-2 (tyrosine hydroxalase) and tph-1 (tryptophan hydroxylase) loss-of-function mutants failed to develop a preference for ethanol. In mammals, chronic ethanol intoxication can lead to tolerance and increased consumption. In worms, Lee et al. (2009) found that chronic exposure to ethanol during development resulted in an even stronger preference for ethanol in adulthood. Thus, early experience can alter behavioral preference for odorants and intoxicants.

\section{Genes mediating learning in more than one paradigm}

Using both forward and reverse genetics, several genes have been identified that are required for learning in multiple paradigms, without being required in neurodevelopment or primary sensory or signal transduction. These genes are the focus of this section.

\section{$g l r-1$}

Described in this review in the section on nonassociative learning, glr-1 encodes an AMPA-type ionotropic glutamate receptor subunit. It was first implicated in a learning paradigm by Morrison and van der Kooy (2001). Taking a candidate gene approach, they showed that $g l r-1$ mutants were impaired in olfactory associative learning but responded normally to both the conditioned stimulus and the unconditioned stimulus. Similar to the reduction in size of GLR-1::GFP clusters associated with long-term mechanosensory habituation (Rose et al. 2003; discussed above), GLR-1::GFP clusters were also smaller following olfactory starvation conditioning (exposure to either the unconditioned or conditioned stimulus alone had no effect) (Stetak et al. 2009). This decrease was dependent upon MAGI-1.

\section{magi-1}

Previously discussed in the section on long-term mechanosensory habituation, MAGI-1 is homologous to mammalian MAGI/ S-SCAM, a multi-PDZ domain synaptic scaffolding protein that interacts with several postsynaptic signaling proteins. Stetak et al. (2009) showed that magi-1 mutants responded normally to volatile and water-soluble cues, as well as starvation but were impaired in the olfactory, gustatory, and thermosensory starvation conditioning assays. Their data suggest that MAGI-1 functions in RIA during associative learning to induce synaptic remodeling of AVA, AVD, and AVE and then functions in AVA and AVD during memory consolidation.

\section{casy-1}

In a genetic screen for $\mathrm{NaCl}$ conditioning mutants, Ikeda et al. (2008) identified casy-1 mutants. casy-1 encodes a calsyntenin/ alcadein ortholog (type I transmembrane proteins with two extracellular cadherin domains). Although it is expressed throughout the nervous system and other tissues, casy-1 expression in ASER was necessary and sufficient for $\mathrm{NaCl}$ conditioning
(Fig. 3; Ikeda et al. 2008). Ikeda et al. (2008) demonstrated that the ectodomain of CASY-1 was the only part of the protein required for $\mathrm{NaCl}$ conditioning and that it was cleaved and released from neurons. They propose that the ectodomain of CASY-1 modulates learning as a signaling molecule; but because $\mathrm{NaCl}$ conditioning required CASY-1 in ASER, the signal must be acting locally, perhaps on ASER itself. CASY-1 functions parallel to the insulin pathway in salt conditioning, as casy-1;ins-1 doublemutants had a more severe learning defect than either single mutant (Ikeda et al. 2008). casy-1 mutants were also impaired in olfactory and thermosensory starvation conditioning assays (Ikeda et al. 2008; Hoerndli et al. 2009). In olfactory conditioning, casy-1 appears to be acting in a glr-1 pathway (Hoerndli et al. 2009), as the $g l r-1$; casy-1 double-mutant was as impaired as either single mutant. Furthermore, glr-1 overexpression rescued the learning defect of casy-1 mutants.

\section{asic-1}

Gated by protons and sensitive to amiloride, acid-sensing ion channels (ASICs) belong to the family of degenerin/epithelial sodium channels. The role of mammalian ASIC-1 in learning (Wemmie et al. 2002, 2004) prompted Voglis and Tavernarakis (2008) to study its C. elegans homolog. They found that asic-1 mutants were impaired in isothermal tracking as well as associative learning assays pairing chemosensory cues with food or starvation. They localized ASIC-1 to the presynaptic terminals of the eight dopaminergic neurons (CEPVL/R, CEPDL/R, PDEL/R, and $\mathrm{ADEL} / \mathrm{R}$ ) and demonstrated that asic-1 mutants had a decreased rate of dopamine release. Olfactory starvation conditioning correlated with an increased rate of dopamine release that was disrupted in asic-1 mutants (Voglis and Tavernarakis 2008).

\section{hen-1}

In an assay devised to study the integration of two sensory signals, worms must cross an aversive $\mathrm{Cu}^{+2}$ barrier to get to a point source of an attractive odorant (Ishihara et al. 2002). Ishihara et al. (2002) conducted a genetic screen with this assay and identified a mutant they named hen-1, for its hesitation in crossing the aversive barrier. In addition to its signal integration phenotype, hen-1 mutants were impaired in salt and thermosensory starvation conditioning (Ishihara et al. 2002). Expressed in ASE and AIY, hen-1 encodes a novel small secreted protein that functions non-cell-autonomously (Ishihara et al. 2002).

\section{Conclusion}

The deterministic development of the worm's nervous system would seem to limit its usefulness as a model to study behavioral plasticity, but time and again the worm has demonstrated its extreme sensitivity to experience-every sensory modality studied can mediate learning. Thus, its deterministic development becomes its greatest asset, as researchers can study behaviors, neurons, and genes in a population of animals with essentially the same "brain." The power of $C$. elegans as a genetic model has led to considerable insights into the cellular and molecular mechanisms underlying learned behaviors. Of particular interest are those genes with no detectable role in the development or primary functioning of neurons, but which are required for learning in multiple paradigms, i.e., asic-1, casy-1, glr-1, magi-1, and hen-1. It will be interesting to determine how these genes and their pathways interact, as many of the mechanisms underlying learning and memory appear to be conserved. For example, mammalian ASIC-1 is involved in learned fear 
behavior (Wemmie et al. 2004), and a SNP in casy-1 ortholog, calsyntenin-2, has been linked to human memory performance (Papassotiropoulos et al. 2006).

Work with C. elegans confirms the importance of learning and memory to survival: Even this relatively small organism shows a large number of degrees of freedom in adapting its behavior to reflect its experience. Thus far, the only limit to worm learning in the laboratory seems to be the creativity of researchers in designing assays to evaluate performance.

\section{References}

Avery L, Shtonda BB. 2003. Food transport in the C. elegans pharynx. J Exp Biol 206: 2441-2457.

Barco A, Bailey CH, Kandel ER. 2006. Common molecular mechanisms in explicit implicit memory. J Neurochem 97: 1520-1533.

Bargmann CI, Horvitz HR. 1991. Chemosensory neurons with overlapping functions direct chemotaxis to multiple chemicals in C. elegans. Neuron 7: $729-742$

Beck CD, Rankin CH. 1995. Heat shock disrupts long-term memory consolidation in Caenorhabditis elegans. Learn Mem 2: 161-177.

Beck CDO, Rankin CH. 1997. Long-term habituation is produced by distributed training at long ISIs and not by massed training at short ISIs in Caenorhabditis elegans. Anim Learn Behav 25: 446-457.

Bernhard N, van der Kooy D. 2000. A behavioral and genetic dissection of two forms of olfactory plasticity in Caenorhabditis elegans: Adaptation and habituation. Learn Mem 7: 199-212.

Bettinger JC, McIntire SL. 2004. State-dependency in C. elegans. Genes Brain Behav 3: 266-272.

Bianchi L, Kwok SM, Driscoll M, Sesti F. 2003. A potassium channel-MiRP complex controls neurosensory function in Caenorhabditis elegans. J Biol Chem 278: 12415-12424.

Biron D, Shibuya M, Gabel C, Wasserman SM, Clark DA, Brown A, Sengupta P, Samuel AD. 2006. A diacylglycerol kinase modulates long-term thermotactic behavioral plasticity in C. elegans. Nat Neurosci 9: $1499-1505$.

Biron D, Wasserman S, Thomas JH, Samuel AD, Sengupta P. 2008. An olfactory neuron responds stochastically to temperature and modulates Caenorhabditis elegans thermotactic behavior. Proc Natl Acad Sci 105: 11002-11007.

Brenner S. 1974. The genetics of Caenorhabditis elegans. Genetics 77: 71-94.

Brockie PJ, Mellem JE, Hills T, Madsen DM, Maricq AV. 2001. The C. elegans glutamate receptor subunit NMR-1 is required for slow NMDAactivated currents that regulate reversal frequency during locomotion. Neuron 31: 617-630.

Burbea M, Dreier L, Dittman JS, Grunwald ME, Kaplan JM. 2002. Ubiquitin and AP180 regulate the abundance of GLR-1 glutamate receptors at postsynaptic elements in C. elegans. Neuron 35: 107-120.

Cai SQ, Wang Y, Park KH, Tong X, Pan Z, Sesti F. 2009. Auto-phosphorylation of a voltage-gated $\mathrm{K}^{+}$channel controls non-associative learning. EMBO J 28: 1601-1611.

Chalfie M, Sulston JE, White JG, Southgate E, Thomson JN, Brenner S. 1985. The neural circuit for touch sensitivity in Caenorhabditis elegans. J Neurosci 5: 956-964.

Cheung BH, Arellano-Carbajal F, Rybicki I, de Bono M. 2004. Soluble guanylate cyclases act in neurons exposed to the body fluid to promote C. elegans aggregation behavior. Curr Biol 14: 1105-1111.

Cheung BH, Cohen M, Rogers C, Albayram O, de Bono M. 2005. Experience-dependent modulation of $C$. elegans behavior by ambient oxygen. Curr Biol 15: 905-917.

Chi CA, Clark DA, Lee S, Biron D, Luo L, Gabel CV, Brown J, Sengupta P, Samuel AD. 2007. Temperature and food mediate long-term thermotactic behavioral plasticity by association-independent mechanisms in C. elegans. J Exp Biol 210: 4043-4052.

Clark DA, Biron D, Sengupta P, Samuel AD. 2006. The AFD sensory neurons encode multiple functions underlying thermotactic behavior in Caenorhabditis elegans. J Neurosci 26: 7444-7451.

Colbert HA, Bargmann CI. 1995. Odorant-specific adaptation pathways generate olfactory plasticity in C. elegans. Neuron 14: 803-812.

Colbert HA, Bargmann CI. 1997. Environmental signals modulate olfactory acuity, discrimination and memory in Caenorhabditis elegans. Learn Mem 4: 179-191.

Davies AG, Pierce-Shimomura JT, Kim H, VanHoven MK, Thiele TR, Bonci A, Bargmann CI, McIntire SL. 2003. A central role of the BK potassium channel in behavioral responses to ethanol in C. elegans. Cell 115: $655-666$.

Dudai Y, Jan YN, Byers D, Quinn WG, Benzer S. 1976. dunce, a mutant of Drosophila deficient in learning. Proc Natl Acad Sci 73: 1684-1688.
Ebrahimi CM, Rankin CH. 2007. Early patterned stimulation produces changes in adult behavior and gene expression in C. elegans. Gens Brain Behav 6: $517-528$.

Emtage L, Chang H, Tiver R, Rongo C. 2009. MAGI-1 modulates AMPA receptor synaptic localization and behavioral plasticity in response to prior experience. PLoS One 4: pe4613. doi: 10.1371/journal.pone. 0004613 .

Feng H, Ren M, Chen L, Rubin CS. 2007. Properties, regulation, and in vivo functions of a novel protein kinase D: Caenorhabditis elegans DKF-2 links diacylglycerol second messenger to the regulation of stress responses and life span. J Biol Chem 282: 31273-31288.

Fu Y, Ren M, Feng H, Chen L, Altun ZF, Rubin CS. 2009. Neuronal and intestinal protein kinase D isoforms mediate $\mathrm{Na}^{+}$(salt taste)-induced learning. Sci Signal 2: ra42. doi: 10.1126/scisignal.2000224.

Gomez M, De Castro E, Guarin E, Sasakura H, Kuhara A, Mori I, Bartfai T, Bargmann CI, Nef P. 2001. $\mathrm{Ca}^{2+}$ signaling via the neuronal calcium sensor-1 regulates associative learning and memory in C. elegans. Neuron 30: 241-248.

Gray JM, Karow DS, Lu H, Chang AJ, Chang JS, Ellis RE, Marletta MA, Bargmann CI. 2004. Oxygen sensation and social feeding mediated by a C. elegans guanylate cyclase homologue. Nature 430: 317-322.

Gray JM, Hill JJ, Bargmann CI. 2005. A circuit for navigation in Caenorhabditis elegans. Proc Natl Acad Sci 102: 3184-3191.

Hedgecock EM, Russell RL. 1975. Normal and mutant thermotaxis in the nematode Caenorhabditis elegans. Proc Natl Acad Sci 72: $4061-4065$.

Hirotsu T, Iino Y. 2005. Neural circuit-dependent odor adaptation in C. elegans is regulated by the Ras-MAPK pathway. Genes Cells 10: 517-530.

Hoerndli FJ, Walser M, Fröhli Hoier E, de Quervain D, Papassotiropoulos A, Hajnal A. 2009. A conserved function of C. elegans CASY-1 calsyntenin in associative learning. PLoS One 4: pe 4880. doi: 10.1371/journal.pone. 0004880.

Hukema RK, Rademakers S, Dekkers MP, Burghoorn J, Jansen G. 2006. Antagonistic sensory cues generate gustatory plasticity in Caenorhabditis elegans. EMBO J 25: 312-322.

Hukema RK, Rademakers S, Jansen G. 2008. Gustatory plasticity in C. elegans involves integration of negative cues and $\mathrm{NaCl}$ taste mediated by serotonin, dopamine, and glutamate. Learn Mem 15: 829-36.

Ikeda DD, Duan Y, Matsuki M, Kunitomo H, Hutter H, Hedgecock EM, Iino Y. 2008. CASY-1, an ortholog of calsyntenins/alcadeins, is essential for learning in Caenorhabditis elegans. Proc Natl Acad Sci 105: 5260-5265.

Ishihara T, Iino Y, Mohri A, Mori I, Gengyo-Ando K, Mitani S, Katsura I. 2002. HEN-1, a secretory protein with an LDL receptor motif, regulates sensory integration and learning in Caenorhabditis elegans. Cell 109: 639-649.

Ito H, Inada H, Mori I. 2006. Quantitative analysis of thermotaxis in the nematode Caenorhabditis elegans. J Neurosci Methods 154: 45-52.

Jansen G, Weinkove D, Plasterk RH. 2002. The G-protein $\gamma$ subunit gpc-1 of the nematode $C$. elegans is involved in taste adaptation. EMBO J 21: 986-994.

Jurado P, Kodama E, Tanizawa Y, Mori I. 2009. Distinct thermal migration behaviors in response to different thermal gradients in Caenorhabditis elegans. Genes Brain Behav 9: 120-127.

Kandel ER, Tauc L. 1965. Heterosynaptic facilitation in neurons of the abdominal ganglion of Aplysia depilans. J Physiol 181: 1-27.

Kano T, Brockie PJ, Sassa T, Fujimoto H, Kawahara Y, Iino Y, Mellem JE, Madsen DM, Hosono R, Maricq AV. 2008. Memory in Caenorhabditis elegans is mediated by NMDA-type ionotropic glutamate receptors. Curr Biol 18: 1010-1015.

Kaye JA, Rose NC, Goldsworthy B, Goga A, L'Etoile ND. 2009. A 3’UTR pumilio-binding element directs translational activation in olfactory sensory neurons. Neuron 61: 57-70.

Kimura KD, Miyawaki A, Matsumoto K, Mori I. 2004. The C. elegans thermosensory neuron AFD responds to warming. Curr Biol 14: $1291-1295$.

Kindt KS, Quast KB, Giles AC, Hendrey D, Nicastro I, Rankin $\mathrm{CH}$ Schafer WR. 2007. Dopamine mediates context-dependent modulation of sensory plasticity in C. elegans. Neuron 55: 662-676.

Kitamura KI, Amano S, Hosono R. 2001. Contribution of neurons to habituation to mechanical stimulation in Caenorhabditis elegans. J Neurobiol 46: 29-40.

Kodama E, Kuhara A, Mohri-Shiomi A, Kimura KD, Okumura M, Tomioka M, Iino Y, Mori I. 2006. Insulin-like signaling and the neural circuit for integrative behavior in C. elegans. Genes Dev 20: 2955-2960.

Kuhara A, Mori I. 2006. Molecular physiology of the neural circuit for calcineurin-dependent associative learning in Caenorhabditis elegans. J Neurosci 26: 9355-9364.

Kuhara A, Inada H, Katsura I, Mori I. 2002. Negative regulation and gain control of sensory neurons by the C. elegans calcineurin TAX-6. Neuron 33: $751-763$. 
Kuhara A, Okumura M, Kimata T, Tanizawa Y, Takano R, Kimura KD, Inada H, Matsumoto K, Mori I. 2008. Temperature sensing by an olfactory neuron in a circuit controlling behavior of C. elegans. Science 320: $803-807$.

Lackner MR, Nurrish SJ, Kaplan JM. 1999. Facilitation of synaptic transmission by EGL-30 Gq $\alpha$ and EGL-8 PLC $\beta$ : DAG binding to $\mathrm{UNC}-13$ is required to stimulate acetylcholine release. Neuron 24: 335-346.

Law E, Nuttley WM, van der Kooy D. 2004. Contextual taste cues modulate olfactory learning in C. elegans by an occasion-setting mechanism. Curr Biol 14: 1303-1308.

Lee RY, Sawin ER, Chalfie M, Horvitz HR, Avery L. 1999. EAT-4, a homolog of a mammalian sodium-dependent inorganic phosphate cotransporter, is necessary for glutamatergic neurotransmission in Caenorhabditis elegans. J Neurosci 19: 159-167.

Lee J, Jee C, McIntire SL. 2009. Ethanol preference in C. elegans. Genes Brain Behav 8: 578-585.

L'Etoile ND, Bargmann CI. 2000. Olfaction and odor discrimination are mediated by the $C$. elegans guanylyl cyclase ODR-1. Neuron 25: 575-586.

L'Etoile ND, Coburn CM, Eastham J, Kistler A, Gallegos G, Bargmann CI. 2002. The cyclic GMP-dependent protein kinase EGL-4 regulates olfactory adaptation in C. elegans. Neuron 36: 1079-1089.

Lüscher C, Frerking M. 2001. Restless AMPA receptors: Implications for synaptic transmission and plasticity. Trends Neurosci 24: 665-670.

Malinow R, Malenka RC. 2002. AMPA receptor trafficking and synaptic plasticity. Ann Rev Neurosci 25: 103-126.

Matsuki M, Kunitomo H, Iino Y. 2006. Goo regulates olfactory adaptation by antagonizing Gq $\alpha$-DAG signaling in Caenorhabditis elegans. Proc Natl Acad Sci 103: 1112-1117.

Miyahara K, Suzuki N, Ishihara T, Tsuchiya E, Katsura I. 2004. TBX2/TBX3 transcriptional factor homologue controls olfactory adaptation in Caenorhabditis elegans. J Neurobiol 58: 392-402.

Mohri A, Kodama E, Kimura KD, Koike M, Mizuno T, Mori I. 2005. Genetic control of temperature preference in the nematode Caenorhabditis elegans. Genetics 169: 1437-1450.

Mori I, Ohshima Y. 1995. Neural regulation of thermotaxis in Caenorhabditis elegans. Nature 376: 344-348.

Morrison GE, van der Kooy D. 2001. A mutation in the AMPA-type glutamate receptor, glr-1, blocks olfactory associative and nonassociative learning in Caenorhabditis elegans. Behav Neurosci 115: 640-649.

Morrison GE, Wen JY, Runciman S, van der Kooy D. 1999. Olfactory associative learning in Caenorhabditis elegans is impaired in lrn-1 and lrn-2 mutants. Behav Neurosci 113: 358-367.

Nuttley WM, Harbinder S, van der Kooy D. 2001. Regulation of distinct attractive and aversive mechanisms mediating benzaldehyde chemotaxis in Caenorhabditis elegans. Learn Mem 8: 170-181.

Nuttley WM, Atkinson-Leadbeater KP, Van Der Kooy D. 2002. Serotonin mediates food-odor associative learning in the nematode Caenorhabditis elegans. Proc Natl Acad Sci 99: 12449-12454.

O'Hagan R, Chalfie M, Goodman MB. 2005. The MEC-4 DEG/ENaC channel of Caenorhabditis elegans touch receptor neurons transduces mechanical signals. Nat Neurosci 8: 43-50.

Palmitessa A, Hess HA, Bany IA, Kim YM, Koelle MR, Benovic JL. 2005. Caenorhabditis elegans arrestin regulates neural G protein signaling and olfactory adaptation and recovery. J Biol Chem 280: 24649-24662.

Papassotiropoulos A, Stephan DA, Huentelman MJ, Hoerndli FJ, Craig DW, Pearson JV, Huynh KD, Brunner F, Corneveaux J, Osborne D, et al. 2006. Common Kibra alleles are associated with human memory performance. Science 314: 475-478.

Pierce-Shimomura JT, Faumont S, Gaston MR, Pearson BJ, Lockery SR. 2001. The homeobox gene lim-6 is required for distinct chemosensory representations in C. elegans. Nature 410: 694-698.

Quinn WG, Harris WA, Benzer S. 1974. Conditioned behavior in Drosophila melanogaster. Proc Natl Acad Sci 71: 708-712.

Rankin CH. 2000. Context conditioning in habituation in the nematode Caenorhabditis elegans. Behav Neurosci 114: 496-505.

Rankin CH, Broster B. 1992. Factors affecting habituation and rate of recovery from habituation in C. elegans. Behav Neurosci 106: 239-249.

Rankin CH, Wicks SR. 2000. Mutations of the Caenorhabditis elegans brain specific inorganic phosphate transporter, eat-4, affecting habituation of the tap-withdrawal response without affecting the response itself. J Neurosci 20: 4337-4344.

Rankin CH, Chiba C, Beck C. 1990. Caenorhabditis elegans: A new model system for the study of learning and memory. Behav Brain Res 37: 89-92.

Remy JJ, Hobert O. 2005. An interneuronal chemoreceptor required for olfactory imprinting in C. elegans. Science 309: 787-790.
Rongo C, Whitfield CW, Rodal A, Kim SK, Kaplan JM. 1998. LIN-10 is a shared component of the polarized protein localization pathways in neurons and epithelia. Cell 94: 751-759.

Rose JK, Rankin CH. 2006. Blocking memory reconsolidation reverses memory-associated changes in glutamate receptor expression. $J$ Neurosci 26: 11582-11587.

Rose JK, Kaun KR, Rankin CH. 2002. A new group training procedure for habituation demonstrates that presynaptic glutamate release contributes to long-term memory in C. elegans. Learn Mem 9: $130-137$.

Rose JK, Kaun KR, Chen SH, Rankin CH. 2003. Glutamate receptor trafficking underlies long-term memory in C. elegans. J Neurosci 23: 9595-9600.

Ryu WS, Samuel AD. 2002. Thermotaxis in Caenorhabditis elegans analyzed by measuring responses to defined thermal stimuli. I Neurosci 22: $5727-5733$.

Saeki S, Yamamoto M, Iino Y. 2001. Plasticity of chemotaxis revealed by paired presentation of a chemoattractant and starvation in the nematode Caenorhabditis elegans. J Exp Biol 204: 1757-1764.

Sanyal S, Wintle RF, Kindt KS, Nuttley WM, Arvan R, Fitzmaurice P, Bigras E, Merz DC, Hébert TE, van der Kooy D, et al. 2004. Dopamine modulates the plasticity of mechanosensory responses in Caenorhabditis elegans. EMBO J 23: 473-482.

Sawin ER, Ranganathan R, Horvitz HR. 2000. C. elegans locomotory rate is modulated by the environment through a dopaminergic pathway and by experience through a serotonergic pathway. Neuron 26: $619-631$.

Shtonda BB, Avery L. 2006. Dietary choice behavior in Caenorhabditis elegans. J Exp Biol 209: 89-102.

Skoulakis EM, Grammenoudi S. 2006. Dunces and da Vincis: The genetics of learning and memory in Drosophila. Cell Mol Life Sci 63: 975-988.

Stetak A, Hörndli F, Maricq AV, van den Heuvel S, Hajnal A. 2009 Neuron-specific regulation of associative learning and memory by MAGI-1 in C. elegans. PLoS One 4: pe6019. doi: 10.1371/journal.pone. 0006019.

Sulston JE, Horvitz HR. 1977. Post-embryonic cell lineages of the nematode, Caenorhabditis elegans. Dev Biol 56: 110-56.

Sulston JE, Schierenberg E, White JG, Thomson JN. 1983. The embryonic cell lineage of the nematode Caenorhabditis elegans. Dev Biol 100: $64-119$

Suzuki H, Kerr R, Bianchi L, Frokjaer-Jensen C, Slone D, Xue J, Gerstbrein B, Driscoll M, Schafer WR. 2003. In vivo imaging of C. elegans mechanosensory neurons demonstrates a specific role for the MEC-4 channel in the process of gentle touch sensation. Neuron 39: 1005-1017.

Sze JY, Victor M, Loer C, Shi Y, Ruvkun G. 2000. Food and metabolic signalling defects in a Caenorhabditis elegans serotonin-synthesis mutant. Nature 403: 560-564.

Tomioka M, Adachi T, Suzuki H, Kunitomo H, Schafer WR, Iino Y. 2006. The insulin/PI 3-kinase pathway regulates salt chemotaxis learning in Caenorhabditis elegans. Neuron 51: 613-625.

Torayama I, Ishihara T, Katsura I. 2007. Caenorhabditis elegans integrates the signals of butanone and food to enhance chemotaxis to butanone. J Neurosci 27: 741-750.

Tsui D, van der Kooy D. 2008. Serotonin mediates a learned increase in attraction to high concentrations of benzaldehyde in aged C. elegans. Learn Mem 15: 844-855.

Vellai T, McCulloch D, Gems D, Kovacs AL. 2006. Effects of sex and insulin/insulin-like growth factor-1 signaling on performance in an associative learning paradigm in Caenorhabditis elegans. Genetics 174: 309-316.

Voglis G, Tavernarakis N. 2008. A synaptic DEG/ENaC ion channel mediates learning in C. elegans by facilitating dopamine signalling. EMBO J 27: 3288-3299.

Wemmie JA, Chen J, Askwith CC, Hruska-Hageman AM, Price MP, Nolan BC, Yoder PG, Lamani E, Hoshi T, Freeman JH, et al. 2002. The acid-activated ion channel ASIC contributes to synaptic plasticity, learning, and memory. Neuron 34: 463-477.

Wemmie JA, Coryell MW, Askwith CC, Lamani E, Leonard AS, Sigmund CD, Welsh MJ. 2004. Overexpression of acid-sensing ion channel 1a in transgenic mice increases acquired fear-related behavior. Proc Natl Acad Sci 101: 3621-3626.

Wen JY, Kumar N, Morrison G, Rambaldini G, Runciman S, Rousseau J, van der Kooy D. 1997. Mutations that prevent associative learning in $C$. elegans. Behav Neurosci 111: 354-368.

White JB, Southgate E, Thomson JN, Brenner S. 1986. The structure of the nervous system of Caenorhabditis elegans. Philos Trans $R$ Soc Lond B Biol Sci 314: $1-340$.

Wicks SR, Rankin CH. 1995. Integration of mechanosensory stimuli in Caenorhabditis elegans. J Neurosci 15: 2434-2444. 
Wicks SR, Rankin CH. 1996. The integration of antagonistic reflexes revealed by laser ablation of identified neurons determines habituation kinetics of the Caenorhabditis elegans tap withdrawal response. J Comp Physiol A 179: 675-685.

Wicks SR, Rankin CH. 1997. The effects of tap withdrawal response habituation on other withdrawal behaviors: The localization of habituation in the nematode Caenorhabditis elegans. Behav Neurosci 111: $342-353$.

Xu X, Sassa T, Kunoh K, Hosono R. 2002. A mutant exhibiting abnormal habituation behavior in Caenorhabditis elegans. J Neurogenet 16: 29-44.

Yamada Y, Ohshima Y. 2003. Distribution and movement of Caenorhabditis elegans on a thermal gradient. J Exp Biol 206: 2581-2593.
Yu S, Avery L, Baude E, Garbers DL. 1997. Guanylyl cyclase expression in specific sensory neurons: A new family of chemosensory receptors. Proc Natl Acad Sci 94: 3384-3387.

Zariwala HA, Miller AC, Faumont S, Lockery SR. 2003. Step response analysis of thermotaxis in Caenorhabditis elegans. J Neurosci 23: 4369-4377.

Zhang Y, Lu H, Bargmann CI. 2005. Pathogenic bacteria induce aversive olfactory learning in Caenorhabditis elegans. Nature 438: $179-184$

Received September 25, 2009; accepted in revised form February 12, 2010. 


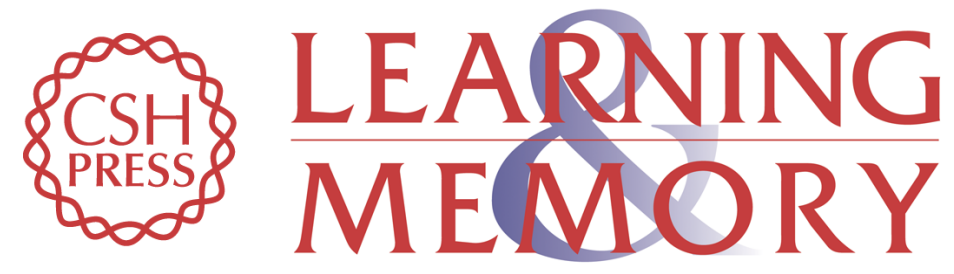

\section{An elegant mind: Learning and memory in Caenorhabditis elegans}

Evan L. Ardiel and Catharine H. Rankin

Learn. Mem. 2010, 17:

Access the most recent version at doi:10.1101//m.960510

References This article cites 105 articles, 41 of which can be accessed free at: http://learnmem.cshlp.org/content/17/4/191.full.html\#ref-list-1

License

Email Alerting Receive free email alerts when new articles cite this article - sign up in the box at the Service top right corner of the article or click here. 